\title{
An Overview of Freight Intelligent Transportation Systems
}

\begin{abstract}
The purpose of this paper is to provide an overview of how the intelligent transportation system (ITS) supports freight transportation operations.

A study of the literature on transportation information and communication technology (ICT) and intelligent (or smart) transportation systems has been conducted. Documents of more than 60 companies producing or using intelligent transportation technologies and systems have been reviewed to provide empirical data regarding freight ITSs. Furthermore, direct observations of some of the systems as well as semi-structured and non-structured interviews with managers of some of the companies have been conducted as secondary sources of empirical data.

As a result of studying the companies, a list of nine freight ITSs is generated; it represents the main freight ITSs. Also, different transportation information types that freight ITS work based on their availability are recognised. The results show that vehicle location systems and condition monitoring systems support and use more transportation information types compared to the other freight ITSs.
\end{abstract}

Keywords: freight intelligent transportation system (ITS), smart transportation management (STM), freight transportation information, performance dimensions, function. 


\section{Introduction}

Information and communication technology (ICT) is considered a tool that enables safe and efficient operations in freight transportation and that improves visibility, responsiveness and performance in supply chains (Giannopoulos, 2004; Coronado Mondragon et al., 2012).

Various information and communication technologies are used to improve the performance of transportation networks. Terms such as "intelligent vehicle," "intelligent highway," "intelligent freight," "intelligent transportation" and "smart transportation" have been introduced by the industry and academic research to identify the advanced information and communication technologies that are or will be used in the future for the management of logistics, transportation and materials handling operations (see Ajmone Marsan et al., 1996; Armingol et al., 2007; Manzie et al., 2007; Lumsden and Stefansson, 2007).

In exhibitions related to logistics and transportation, companies introduce their new services and technologies under the titles smart or intelligent (e.g., the annual conference and exhibition of Intelligent Transportation Systems World Congress and the ITS in Europe Congress). Transportation organisations and regulation makers of different countries have established ITS groups to improve their understanding of such systems in order to manage and control both passenger and freight transportation operations (e.g., ITS Europe, ITS America, ITS Japan, ITS Sweden).

By using ITSs, logistics operations could be improved by enhancing the exchange of information and real-time status updates regarding different business operations in different modes of transportation (Schumacher et al., 2011). ITS has led to improvements in the efficiency and safety of railway transportation (Kumar and Kumari, 2012). Maritime transport has recently gained increased attention, especially in connection to the building and further development of ITSs (Pietrzykowski, 2011).

The current ITSs collect an enormous amount of data about the operations of transportation systems and transmit data in different forms to be used by authorities, carriers and other actors in the transportation networks. According to Crainic et al. (2009), some of this collected and transmitted data is not useful, and in many cases highly detailed data is still processed and acted upon by human operators who do not have sufficient decision-support tools. Identification of the types of transportation information used or supported by ITS and of their effect on transportation functions and performance dimensions is an initial step towards making such systems more effective for operators. It might lead to a more effective way of satisfying the information demands of actors in freight transportation networks. According to Bekiaris and Nakanishi (2004), the complex aims and effects of ITS concerning efficiency, safety and the environment make the evaluation of ITS a complicated task. A review of the literature on this subject indicates that it lacks a general overview of the way ITSs contribute to supporting transportation functions and improving performance dimensions in light of the types of information used or supported by such systems.

The purpose of this paper is to present an overview of how ITSs support freight transportation operations. This overview is based on the study of various freight ITSs and technologies. The most common freight ITSs are identified, as are the types of freight transportation information 
most frequently used or supported by freight ITSs. The supported transportation functions and improved transportation performance dimensions after using the freight ITS are identified and described.

The terms intelligent transportation system (ITS) and smart transportation management (STM) systems are used interchangeably in the literature to refer to the advanced information and communication systems used for managing and controlling transportation operations (see Wootton et al., 1995; Crainic et al., 2009; Stefansson and Lumsden, 2009; El- Faouzi et al., 2010). These terms are almost identical in meaning. In this paper, the term freight ITS is used for the investigation of such systems.

The transportation information mentioned frequently in the paper refers to the data and information essential for managing and controlling freight transportation operations in the transportation network. Such operations include shipment of the freight, inventory management, materials handling and operations at terminals and ports.

\section{Method}

A research design represents the logic that links the data to be collected to the initial question(s) of a study (Flick, 2006). In this study, through systematic strategies, the researcher gathers information in order to advance interpretations of how ITS improves different functions and performance dimensions in logistics and transport operations (Marshall and Rossman, 2006). This study is designed according to the steps described below.

First, the literature on intelligent (and smart) transportation systems and transportation ICT is studied to identify the definitions of such transportation systems and determine their elements.

Documents and published case studies from different companies in the field of freight ITS have been reviewed. Documents are considered sources of empirical data not produced at the request of a business researcher; instead, they are pre-existing objects waiting to be collected and analysed (Bryman and Bell, 2007). The review has been conducted to determine what types of freight transportation information are used or supported by applying freight ITS and what transportation functions and performance dimensions are supported or improved by using freight ITS. The selection of an appropriate population for case study research controls irrelevant variation and helps to define the limits of generalising the findings (Eisenhardt, 1989). Documents from more than 60 companies producing or using intelligent transportation technologies and systems are reviewed. These documents include projects, progress reports, articles in industrial magazines, catalogues of the systems produced by the companies and the information available on the companies' websites (Yin, 2003; Bryman and Bell, 2007).

In some cases the information in the companies' documents does not make possible a clear identification of the information types used or supported by the systems. In such cases direct observations of some of the systems have been conducted as another source of data for triangulation (Yin, 2003). The author has attended demonstrations of some of the systems and has observed some of the systems by visiting freight ITS laboratories and test centres. 
For some of the documents, the applications of the studied freight ITS for supporting or improving transportation functions and performance dimensions have not been clarified. Therefore, complementary interviews with managers of the companies in the form of semistructured and non-structured interviews have been conducted to fulfil the objectives of the study (Marshall and Rossman, 2006). Some of the interviews have been conducted during exhibitions and conferences on logistics and on transportation and intelligent transportation systems, where representatives from the industry and academia presented their latest achievements in this area. Follow-up email correspondence and telephone conversations with the contact persons from the companies have been conducted to ensure the validity of the data collected from a number of the companies.

Practical and credible methods of analysis lead to drawing valid inferences from qualitative data (Miles and Huberman, 1994). A list of intelligent or smart transportation systems is provided according to the collected empirical data. The collected systems are then categorised into nine major freight ITSs. An analysis has been conducted to identify the information types used or supported by the systems and the transportation functions and transportation performance dimensions supported or improved by freight ITS. Considering the rapid development of freight ITS and the lack of agreed-upon definitions and terminology in this area, there is a risk of missing some of the systems. The same system or service is sometimes introduced by different names or titles in the literature. In such cases, this study places similar systems with almost the same functionalities in the same group, and it uses the most frequent and appropriate name to introduce them.

The results of the empirical studies have been reviewed by researchers in the transportation information systems field to improve the validity and reliability of the research.

The results of the empirical studies are compared to the findings of related published literature in this area. The papers that have generated similar results are used as references to improve the validity of the empirical findings.

The flow chart in Figure 1 illustrates the different steps by which the empirical studies for this paper have been conducted.

\section{[Figure 1 is located here]}

\section{ICT for freight transportation}

ICT is considered a tool for enhancing supply chain performance (Sundarakani et al., 2012).

Application of ICT can lead to improvements in warehousing activities and customer service (Zeimpekis et al., 2010). Different types of economic benefits including reduced costs of logistics operations are achieved through application of ICT (Chan et al, 2012).

One important advantage of ICT is improved safety and efficiency in freight transport operations resulting from improvements in the exchange of information between the actors in supply chains (Giannopoulos, 2004; Vilko et al., 2012). Furthermore, information and communication applications and services in the field of freight transportation can support the integration of intermodal transportation through supply chains. 
Among the papers written on applications of ICT for freight transportation, Giannopoulos (2004) has presented a proper categorisation of ICT functions for freight transportation operation. According to this categorisation, ICT will contribute to three main groups of functions for freight transport: resource management; ports and terminals operations management; and tracking and tracing. These three functions are described below.

- Transportation resource management: This function is related to the control of transportation resources such as load units, trucks, trains, ships and containers. This category includes the ICT for improving the flow of information used for resource management systems, freight information systems for cargo terminals and integrated route planning systems with online communication. The application of such systems has led to decreased delivery times to the customers and the reduction of errors (Giannopoulos, 2004).

- Ports and terminals operations management: This function enables the control of the flow of material through the ports and terminals. It is supported by using systems for optimising the performance of the ports and terminals, ICT for intermodal terminals and data exchange systems. Different technologies are applied for improving this function, and they have improved the efficiency of different ports and terminals by decreasing error rates and increasing loading speed (Durr and Giannopoulos, 2003; Hsu et al., 2009).

- Freight and vehicle tracking and tracing: This function enables the monitoring and control of the location of vehicles and freight in the transportation network. Different information systems exist to control and regulate the location, physical condition, position and security of goods and vehicles (Chow et al., 2006).

\section{Freight intelligent (or smart) transportation systems}

The growing number of participants in transport operations has led to an increased complexity in logistics networks with increased demand for information flow between participants in distribution setups (Stefansson and Lumsden, 2009). Furthermore, awareness of the current transportation systems' capacity limitations has been a driving force in the search for methods leading to a more efficient usage of the current infrastructure capacities. This demand has been an initiative for shaping a new kind of transportation management system, that is, the smart or intelligent transportation system (ITS), which moves data and information more effectively between partners, increases freight visibility, monitors involved activities in a better way, and increases interactions with logistics infrastructure information (Stefansson and Lumsden, 2009). Application of ITS creates greater opportunities for improving the performance of all modes of transport (Pietrzykowski, 2011). Crainic et al. (2009) have defined ITS as "the latest technologies, infrastructure, and services as well as the operations, planning and control methods that are used for the transportation of passengers and freight." Different fields of technology such as communications, computing hardware, positioning systems, telecommunications, vehicle technologies, electronics and sensors have become integrated and shaped the concept of ITS. This support leads to improvements in the performance of transportation operators. ITS is being used in different areas related to freight transportation, including the following: fleet management and control; controlling the 
position, condition, placement and identification of freight and vehicles; and city logistics. Such systems can increase the fluidity of truck traffic, offer seamless border crossings and ensure adequate levels of control and reporting that lead, in turn, to higher levels of safety and greater efficiency in transportation systems (Kumar and Kumari, 2012; Coronado Mondragon et al., 2012). They also have the potential for creating value-adding services for businesses and consumers (Schumacher et al., 2011).

\section{Freight ITS and the dimensions of transportation performance}

Evaluations of the performance of transportation systems focus on the economic, social and environmental impacts of such systems. An overview of the value of ITS for transportation operations requires well-defined analysis criteria covering these three impacts. For this purpose, three performance dimensions are defined for a part of overview of the value of freight ITS for supply chain operations; they are efficiency and effectiveness, safety and security and environmental performance. In industrial reports and the academic literature, these performance dimensions are used as criteria of analysis for the evaluation of freight ITS (e.g., Bekiaris and Nakanishi, 2004; Teodorovic and Lucic, 2006; Vanderschuren, 2008; Jacob and Feypell, 2010). These dimensions are described below.

- The first performance dimension is efficiency and effectiveness, which is related to the application of ITS to transportation resources, including vehicles, infrastructure and human resources, in a way that fulfils the demands in an optimal and appropriate fashion. In many cases, increasing the efficiency and effectiveness of transportation systems leads to economic advantages. For example, reducing the travel time of trucks or reducing error rates leads to efficiency of transportation and, at the same time, to economic advantages for supply chain actors.

- The second performance dimension is safety and security, which is related to applications of freight ITS for improving the protection of transported freight and people. Safety and security are social aspects of transportation to which freight ITS may contribute.

- The third dimension is environmental performance, which is related to reducing the negative impacts of transportation on the environment. The environmental dimensions of transportation can lead to social and economic consequences as well.

\section{Empirical study}

ITSs are used in both the freight and passenger transportation sectors. Considering the scope of this research on freight transportation, the freight-related ITSs are identified through empirical studies (freight ITS).

Based on a review of the documents of freight ITS-related companies, this paper identifies the types of transportation information supported by freight ITSs. These are called transportation information types (Lumsden and Mirzabeiki, 2008). Support for the freight transportation information is preparing the data and information, exchange of data between partners of the freight transportation network and also increasing quality aspects of data such as accuracy, timeliness and speed of data transmission. The effects of such information 
systems on the improvement of the functions and significant performance dimensions of transportation are recognised in the subsequent steps. The transportation functions analysed in this paper are as follows: transportation resource management, ports and terminals operations management and freight and vehicle tracking and tracing. They are the main functions of information and communication technologies for transportation operations (Giannopoulos, 2004).

The transportation performance dimensions supported by ITS, and hence analysed in this paper, are as follows: efficiency and effectiveness, security and safety and environmental performance. The steps of analysis conducted in this paper are illustrated in Figure 2.

\section{[Figure 2 is located here]}

\subsection{Freight transportation information types}

The information types listed below represent the types of transportation information supported or used by freight ITS according to the empirical studies. In other words, the application of freight ITS is based on the availability of such information. Each type of information contains sub-types, some of which are mentioned in the list below. Types of information not mentioned in the list may exist. The list includes the transportation information types most frequently used or supported by freight ITS based on the empirical studies conducted for this paper.

- Traffic and infrastructure information: Real-time traffic information effectively improves traffic flow and the efficient usage of roads (Fukui et al., 2009). Information regarding the location of roads, the status of roads (e.g., road quality or temporary construction), types of vehicles that can utilise the road, limitations and congestion and collisions or other incidents is related to this type of transportation information.

- Vehicle and freight location information: This type of transportation information enables the tracking and tracing of freight through the transportation network (Mirzabeiki and Sjöholm, 2012). Such information includes notifications regarding the arrival of freight to an actor, loading and unloading information for freight shipment, geographical location of freight accessible through vehicle location and condition monitoring systems and location of the freight in the warehouses, terminals and ports.

- Freight condition information: Such information is related to the physical attributes of the product during transportation operations, including when the product is stored in warehouses or when it is shipped by vehicles between actors in the transportation network Real-time information regarding the temperature level, pressure level, impact, humidity or the level of light in the vehicle during transportation makes up the subcategories of this transportation information type. Recently, governmental authorities in Europe have expressed safety and quality concerns regarding the availability of such information for food products (Sundarakani et al., 2012).

- Freight positioning information: Such information is related to the placement and sequencing of the products when they are stored or being shipped. Examples of such 
information include information related to the positioning of the products in warehouses, presented on a three-axis grid, and information related to the placement of containers in the Ro-Ro ships (Lumsden et al., 1997). Having such information is essential for reliable and efficient warehouse and material handling operations (Poon et al., 2009).

- Warehouse operations and inventory information: Such transportation information includes information related to the number of items in the warehouses, customers' orders for different items, loading and unloading times for different orders and information about the contents of different warehouses. Accuracy of the number and types of items stored in the warehouses is an important parameter for this information type. Different studies have evaluated the value of inventory data for supply chain actors (Borders et al., 2008).

- Cargo information: Information regarding types of shipped items, their attributes (such as model, class, size, colour, weight, price and ID number, as well as other kinds of data that depend on the type of items), sender information, receiver information and information regarding the quantity of shipped items is a significant factor for the control and management of transportation operations. This information is used by transportation operators such as transportation companies, ports and terminals and senders and receivers of the cargo, as well as by authorities such as customs services on the borders and police. New technologies and equipment are used for controlling the cargo in inspection procedures conducted by the authorities (Duan et al., 2009). Systems for scanning and auto-identifying the products contribute to the support of such information and to reducing the errors associated with it.

- Vehicle identity information: Information such as the type and class of vehicles, their registration numbers and other identification information is used in different transportation operations for transportation resource management. Such information is also used by authorities for controlling the security of transportation operations. License plate recognition is an important research area in transportation and has been broadly studied in the last two decades (Thome et al., 2011).

\subsection{Freight ITS}

Based on the collected empirical data, the freight ITSs most commonly applied to transportation operations are categorised into nine systems. The use of each system to support the functions of transportation and the contribution of each system to the improvement of different performance dimensions of transportation (effectiveness and efficiency, safety and security and environmental performance) is described below. The results of the empirical studies are compared to the findings of related published literature in this area. The papers that have similar findings are used as references to improve the validity of the empirical findings. The identified freight ITSs are as follows:

- Traffic control and monitoring systems: Such systems are created for controlling and managing traffic flow by providing information regarding traffic situations, such as collisions, congestion, traffic flow speed and vehicles on the roads to be used by authorities or by logistics service providers. Such information is used for controlling 
the safety and security of transportation operations. Different technologies such as smart traffic lights, variable traffic signs and cameras for plate recognition and speed measurement equipped with sensors are used in such information systems. These systems might affect the resource planning and management of vehicles by improving the safety and efficiency of transportation operations. By using such systems, actors can send updates about their arrival time or delay notifications, which enhance the efficiency of trucks, ports and terminal operations. The environmental performance of transportation operations is improved by decreasing transportation time and results in a more harmonised traffic flow (see Li et al., 2007).

- Weight-in-motion (WIM) systems: These systems are created for to control and weigh vehicles to increase transportation safety and reduce the damages caused by overweighted vehicles. WIM systems can improve performance by eliminating the stop times of the trucks on the static weight control systems. Some of the applications of such systems are legislation, regulations and administration of the transportation. Besides the cost of road maintenance, damages of infrastructure lead to environmental threats. Jacob and Feypell (2010) have identified the advantages of WIM systems and their importance for improving transportation operations. According to their study, WIM systems reduce the risk of accidents involving over-weighted vehicles, reduce damages to the infrastructure such as roads or bridges and lead to time savings for both truck drivers and police.

- Delivery space booking systems: These systems allow the space for parking to be booked for a specific vehicle to load or unload freight during a specific time period. Such systems are quite useful in urban areas with space limitations resulting from the presence of retailers in large city centres. Also, they might be used for the terminals. These systems contribute to the environmental and efficiency/effectiveness performance dimensions by eliminating the non-value-adding time spent searching for parking spaces. Teodorovic and Lucic (2006) have discussed the need for intelligent parking booking systems and have proposed strategies for designing such systems. According to their study, the application of these systems reduces the total number of vehicle trips during a specific time period (contributing to environmental performance) and maximises the utilisation of the parking space (contributing to the efficiency of transportation infrastructure).

- Vehicle location and condition monitoring systems: These systems provide real-time information about the position of the vehicles on the map by transmitting the information via satellite. Such information is provided for the users via the Internet. By installing sensors on the vehicle's container, the system can provide real-time information regarding the condition of the freight during shipment. It has the capability of real-time control regardless of whether the container's door is locked or unlocked. It enables better fleet management and improved tracking and tracing of goods and vehicles. For example, having real-time information about the location of trucks on the roads allows the customs service providers to identify the arrival time of vehicles and prepare the documentation on the borders, which reduces the waiting times of the trucks behind the borders. By using such information port operators can send expected arrival time updates to the trucks when the ships are delayed. Also, 
these systems allow drivers to identify safe and unsafe parking zones. They lead to the improvement of the security and safety of transportation. The dimensions of transportation supported by such systems are effectiveness/efficiency and security/safety. According to $\mathrm{Lu}$ et al. (2007), the application of integrated vehicle tracking systems is useful as a dimension of decision support systems for transportation resource management and logistics management.

- Route planning systems: Such systems are used to plan transportation routes in response to road situations. As a result, the effectiveness of operations is increased by providing a better level of service to the customers through reducing the potential for delays. As a result of reduced waiting times on the roads, the operations become more eco-friendly. Using such systems leads to better resource planning for transportation operators. According to Taniguchi and Shimamoto (2004), dynamic vehicle routing and scheduling will benefit carriers by reducing their costs, customers by providing a better level of service and the environment by reducing traffic congestion.

- Driving behaviour monitoring and control systems: These systems analyse the speed and acceleration of drivers during transportation operations, and they provide feedback for improving driving. Such feedback leads to reduced fuel consumption by vehicles and therefore results in more eco-friendly transportation. Therefore, it supports transportation resource management. Also, using technologies for improving the concentration of drivers leads to a reduction in accidents and to an improvement of the safety of operations (see Marell and Westin, 1999).

- Crash preventing systems: Technologies such as sensors are used in these systems to reduce the probability of accidents. For example, sensors installed on a car can warn drivers when they get close to an object. Another kind of crash preventing system can detect objects and provide information regarding the probability of accidents by measuring the distance between vehicles via the transportation infrastructure. If a pedestrian jumps in front of a vehicle a signal is sent to the other vehicle and leads to the prevention of an accident. Such systems increase the safety of transportation operations by reducing the probability of accidents. Systems for the detection of pedestrians at night are an example of this group. Tsugawa et al. (1997) have described how the structure of intelligent vehicle/highway systems (IVHSs) increases transportation safety. Moreover, Chira-Chavala and Yoo (1994) have demonstrated that application of cruise control systems leads to a reduction in the number of traffic accidents.

- Freight location monitoring systems: The application of RFID (Radio Frequency Identification) tags without the need of direct light contact for scanning has created an advantage for transportation operations. Installing RFID readers on vehicles or warehouse doors allows freight movement to be automatically controlled and recorded in the information systems' databases. Using auto-identification (auto-ID) systems has provided new capabilities such as reading a large number of tags at the same time, and has decreased the number of errors caused by manual data entry. It has also reduced inaccuracies regarding the number of items in inventories during warehousing or in vehicles during shipping (see Hardgrave et al., 2009). Using auto-ID based tracking and tracing systems leads to the easy location of items in big warehouses, ports and 
terminals. Using such systems to decrease loading and unloading time and to increase the accuracy of cargo information leads to better resource management. Such systems improve the safety and security of transported items by increasing the visibility of freight location. For example, auto-ID technologies can help to reduce the number of stolen items or to distinguish fake from original items. Also, the use of such systems for waste management contributes to better environmental performance. According to Chow et al. (2006), the application of such systems for warehouse operations leads to improved working efficiency, reduced operations cost, enhanced customer satisfaction and time savings in resource management activities.

- Freight status monitoring systems: The application of different sensors for measuring the physical attributes of goods, such as temperature, humidity, impact level, light level and vibration level, can create improvements in transportation operations. Recently, there has been an increased application of such systems for controlling medicines, dangerous goods and fresh food. A combination of the sensors with autoID technologies such as RFID provides new opportunities for better control and monitoring of the flow of material between different actors in the supply chains. Jedermann et al. (2006) have shown that the application of RFID technology combined with sensors leads to improvements in the quality of transported food. The application of such systems leads to greater efficiency in transportation operations. Using them to control the shipment of chemicals, explosives and other dangerous goods can result in safer and more eco-friendly transportation.

\subsection{Transportation information types, functions and performance dimensions}

A summary of the analysis conducted in the previous chapter is presented in Table 1. The first column of Table 1 lists the nine freight ITSs generated from the empirical studies conducted for this paper. The transportation information types used or supported by the systems and the transportation functions and transportation performance dimensions improved as a result of using the systems are identified in the other columns of Table 1.

The list of ITSs shows that vehicle location systems and condition monitoring systems support more transportation information types compared to the other freight ITSs. Also, these systems support all three transportation functions. Freight location monitoring systems and freight status monitoring systems support many transportation information types as well. The empirical studies conducted by the author indicate an interest among supply chain managers to apply freight location monitoring systems to increase the traceability of products across the entire supply chain, from the raw material suppliers to the final customers. A number of European projects (e.g., the projects Indisputable Key and Euridice) are currently investigating the feasibility and probability of the application of radio frequency technology for auto-identification and for tracing items across the supply chain. The empirical studies conducted for this paper indicate that the application of freight location monitoring systems and freight status monitoring systems support all three transportation performance dimensions. 


\section{[Table 1 is located here]}

Among the freight ITSs on the list, driving behaviour monitoring and control systems, delivery space booking systems and the crash preventing system support the fewest transportation information types.

A comparison of the different transportation information types in Table 1 indicates that traffic and infrastructure information is the transportation information type used or supported by the largest number of freight ITSs on the list. The documents of different freight ITS-related companies suggest that there is a focus on supporting this information type. Different systems and services applying advanced technologies are created to increase the visibility or timeliness of such information for actors in the transportation setups. Moreover, the empirical studies conducted by the author indicate that the application of such information is more effective for congested areas. Vehicle identity information, vehicle and freight location information and cargo information are used or supported by a large number of freight ITSs as well.

A comparison of the transportation functions indicates that transportation resource management and ports and terminal operations management are supported by a larger number of freight ITSs compared to freight and vehicle tracking and tracing. Freight ITSs help transportation resource management and ports and terminal operations management to utilise transportation resources in a more effective and efficient way.

According to Table 1, comparisons between the improved transportation performance dimensions do not indicate a significant difference. An interesting point of this comparison is the contribution of freight ITS to the environmental dimensions of logistics and transportation. The empirical studies conducted by the researcher indicate an increasing interest among manufacturers, governmental authorities, transportation operators and other stakeholders in the transportation network in establishing more eco-friendly transportation operations. Considering the large amount of emissions produced by transportation, those studies indicates that the information and communication contribute to more sustainable environmental practices.

Figure 3 illustrates the ways in which freight ITSs support transportation operations.

\section{[Figure 3 is located here]}

As illustrated in the box on the left side of Figure 3, the freight ITSs use different types of information regarding vehicles, transportation infrastructure and transported freight. Such information is saved in the databases of the information systems of different actors in the transportation networks, and the authorities and actors share such information for different purposes. Moreover, freight ITSs support different types of information regarding transportation operations. This support could be in the form of increased availability, visibility, timeliness, speed and accuracy of the information regarding the transportation of 
products. It leads to improvements in transportation operations by supporting different transportation functions and by improving different transportation performance dimensions, as illustrated in the box on the right side of Figure 3. This study analyses the transportation functions that are, according to the literature, the main functions supported by the information and communication technologies in transportation. These functions are transportation resource management, port and terminal operations management, and freight and vehicle tracking and tracing. The main performance dimensions of transportation operations analysed in this paper are efficiency and effectiveness, safety and security and environmental performance. The main environmental aspects of transportation improved by using freight ITS include waste management, reductions in the harmful consequences of road damage and decreases in emissions by reducing unnecessary transportation and waiting times of vehicles on the road. The use of different freight ITSs to support different types of transportation information could provide general indicators for the effects of such systems on transportation operations.

According to Crainic et al. (2009), a definitive assessment of the effectiveness of ITSs has not yet been conducted, and the studies of freight ITS could indicate what has been achieved and what could be achieved in this area in the future. In order to determine the effectiveness of such systems, further investigation needs to be conducted on the value of the supported information types and supported transportation activities for transportation operators, and it needs to be compared with the support level of freight ITS for such information and activities. The effectiveness of a freight ITS could be different for various actors in the transportation network depending on their demand for different types of information and their need for conducting different activities according to their role in the network.

\section{Conclusions}

The empirical studies conducted for this paper indicate that the most common freight ITSs are as follows: traffic control and monitoring systems, weight-in-motion systems, delivery space booking systems, vehicle location and condition monitoring systems, route planning systems, driving behaviour monitoring and control systems, crash preventing systems, freight location monitoring systems and freight status monitoring systems. The types of information most frequently used or supported by such freight ITSs include the following: traffic and infrastructure information, vehicle and freight location information, freight condition information, freight positioning information, warehouse operations and inventory information, cargo information and vehicle identity information.

This paper provides an understanding of the meaning and definition of freight ITS and provides insights into how it supports different functions in transportation operations. Considering the lack of an agreed-upon definition for freight ITS in the literature and industrial reports, and assuming rapid improvements in new technologies and systems applied in freight transportation, this understanding represents an important theoretical contribution.

The paper also makes some practical contributions. It provides knowledge regarding the new application of ICT for freight transportation and presents the results of empirical studies as well as of the published literature on this subject. This information provides useful knowledge for practitioners and logistics managers. 
The implementation and efficient application of freight ITS, especially in inter-organisational environments, is an issue of concern for practitioners. Utilisation of the new ICT requires different supply chain actors to share both data and the costs of the system hardware and software. Another important barrier to the integrated application of such systems is related to the lack of standardised information exchange methods and processes. Further empirical studies in the form of deep case studies and action research are needed for exploring different issues related to the implementation of such systems for inter-organisational purposes. Such studies could provide valuable knowledge for practitioners utilising ICT to support freight transport operations.

\section{Acknowledgements}

The author would like to thank the editor and the reviewers of the International Journal of Logistics Systems and Management for their valuable feedback on this paper.

\section{References}

Ajmone Marsan, M., Taricco, G., Roncarolo, G., Tagliente, G. (1996) 'Simulation of three MAC protocols for intelligent highway packet radio networks', Computer Communications, Vol. 19 No. 12, pp. 943-953.

Armingol, J.M., Escalera, A., Hilario, C., Collado, J.M., Carrasco, J.P., Flores, M.J., Pastor, J.M., Rodriguez, J. (2007) 'IVVI: Intelligent vehicle based on visual information', Robotics and Autonomous Systems, Vol. 55 No. 12, pp. 904-916.

Bekiaris, E., and Nakanishi, Y. (Eds.) (2004) Economic impacts of intelligent transportation systems: Innovations and case studies, Research in transportation economics, 8. Elsevier, Oxford.

Borders, B.E., Harrison, W.M., Clutter, M.L., Shiver, B.D., Souter, R.A. (2008) 'The value of timber inventory information for management planning', Canadian Journal of Forest Research, Vol. 38 No. 8, pp. 2287-2294.

Bryman, A., and Bell, E. (2007) Business research methods, Oxford University Press, Oxford.

Chan, X., Lau, Y., Ng, J.M.J. (2012) 'Critical evaluation of ERP implementation on firm performance: A case study of AT\&T', International Journal of Logistics Systems and Management, Vol. 12 No. 1, pp. 52-69.

Chira-Chavala, T., and Yoo, M. (1994) 'Potential safety benefits of intelligent cruise control systems', Accident Analysis and Prevention, Vol. 26 No. 2, pp. 135-146.

Chow, H.K.H., Choy, K.L., Lee, W.B., Lau, K.C. (2006) 'Design of a RFID case-based resource management system for warehouse operations', Expert Systems with Applications, Vol. 30 No. 4, pp. 561-576. 
Coronado Mondragon, A.E, Lalwani, C.S, Coronado Mondragon, E.S., Coronado Mondragon, C.E., Pawar, K.S. (2012) 'Intelligent transport systems in multimodal logistics: A case of role and contribution through wireless vehicular networks in a sea port location', International Journal of Production Economics, Vol. 137 No.1, pp. 165175.

Crainic, T.G., Gendreau, M., Potvin, J. (2009) 'Intelligent freight transportation systems: Assessment and the contribution of the operations research', Transportation Research Part C, Vol. 17 No. 4, pp. 541-557.

Duan, X., Cheng, J., Zhang, L., Xing, Y., Chen, Z., Zhao, Z. (2009) 'X-ray cargo container inspection system with few view projection imaging', Nuclear Instruments and Methods in Physics Research A, Vol. 598 No. 2, pp. 439-444.

Durr, E., Giannopoulos, G.A. (2003) 'SITS: A system for uniform intermodal freight transport information exchange', International Journal of Transport Management, Vol. 1 No.3, pp. 175-186.

Eisenhardt, K.M. (1989) 'Building theories from case study research', The Academy of Management Review, Vol. 14 No.4, pp. 532-550.

El-Faouzi, N.E., Leung, H., Kurian, A. (2010) 'Data fusion in intelligent transportation systems: Progress and challenges-A survey', Information Fusion, Vol. 12 No. 1, pp. 4-10.

European Inter-Disciplinary Research on Intelligent Cargo for Efficient, Safe and Environment-Friendly Logistics (Euridice) [online] available at: http://www.euridiceproject.eu (Accessed 27 August 2012).

Flick, U. (2006) An introduction to qualitative research, SAGE Publications, London.

Fukui, M., Nishinari, K., Yokoya, Y., Ishibashi, Y. (2009) 'Effect of real-time information upon traffic flows on crossing roads', Physica A: Statistical Mechanics and Its Applications, Vol. 388 No. 7, pp. 1207-1212.

Giannopoulos, G.A. (2004) 'The application of information and communication technologies in transport', European Journal of Operational Research, Vol. 52 No. 2, pp. 302-320.

Hardgrave, B.C., Aloysius, J., Goyal, S. (2009) 'Does RFID improve inventory accuracy? A preliminary analysis', International Journal of $R F$ Technologies: Research and Applications, Vol. 1 No. 1, pp. 44-56.

Hsu, C. I., Shih, H. H., Wang, W. C. (2009) 'Applying RFID to reduce delay in import cargo customs clearance process', Computers and Industrial Engineering, Vol. 57 No. 2, pp. 506-519.

Indisputable Key project [online] available at: http://www.indisputablekey.com/ (Accessed 27 August 2012). 
ITS World Congress [online] available at: http://www.itsworldcongress.com/ (Accessed 27 August 2012).

ITS in Europe Congress [online] available at: http://2011.itsineurope.com/ (Accessed 27 August 2012).

ITS Sweden [online] available at: http://www.its-sweden.se/ (Accessed 27 August 2012).

ITS America [online] available at: http://www.itsa.org/ (Accessed 27 August 2012).

ITS Japan [online] available at: http://www.its-jp.org/english/ (Accessed 27 August 2012).

ITS in Europe Congress [online] available at: http://2011.itsineurope.com/ (Accessed 27 August 2012).

Jacob, B., Feypell-de La Beaumelle, V. (2010) 'Improving truck safety: Potential of weightin-motion technology', IATSS Research, Vol. 34 No. 1, pp. 9-15.

Jedermann, R., Behrens, C., Westphal, D., Lang, W. (2006) 'Applying autonomous sensor systems in logistics-Combining sensor networks, RFIDs and software agents', Sensors and Actuators A: Physical, Vol. 132 No. 1, pp. 370-375.

Kumar, N., Kumari, N. (2012) 'Conceptual architectural design of Indian railway intelligent transportation systems', Communication Technologies for Vehicles, Vol. 7266, pp. 151162.

Li, L., Liu, Y.A., Tang, B.H. (2007) 'SNMS: An intelligent transportation system network architecture based on WSN and P2P network', The Journal of China Universities of Posts and Telecommunications, Vol. 14 No. 1, pp. 65-70.

Lu, M., Chen, W., Shen, W., Lam, H.C., Liu, J. (2007) 'Positioning and tracking construction vehicles in highly dense urban areas and building construction sites', Automation in Construction, Vol.16 No. 5, pp. 647-656.

Lumsden, K., and Stefansson, G. (2007) 'Smart freight to enhance control of freight transportation networks', International Journal of Logistics Systems Management, Vol. 3 No. 3, pp. 315-329.

Lumsden, K., Mirzabeiki, V. (2008) 'Determining the value of information for different partners in the supply chain', International Journal of Physical Distribution \& Logistics Management, Vol. 38 No. 9, pp. 659-673.

Lumsden, K., Roudolphe, P., Sjöstedt, L. (1997) 'Information as a value adder for the transport user', Division of Logistics and Transportation, Chalmers University of Technology, Göteborg, Sweden.

Manzie, C., Watson, H., Halgamuge, S. (2007) 'Fuel economy for urban driving: Hybrid vs. intelligent vehicles', Transportation Research Part C, Vol. 15 No. 1, pp.1-16. 
Marell, A., Westin, K. (1999) 'Intelligent transportation systems and traffic safety-Drivers perception and acceptance of electronic speed checkers', Transportation research Part C, Vol. 7 No. 2-3, pp.131-147.

Marshall, C., Rossman, G.B. (2006) Designing qualitative research, SAGE Publications.

Miles, M.B., Huberman, A.M. (1994) Qualitative data analysis, Sage Publications, Thousand Oaks, CA.

Mirzabeiki, V., Sjöholm, P. (2012) 'Sharing tracking and tracing data to improve operations of supply chain actors', International Journal of Logistics Systems and Management, Vol. 13 No. 1, pp. 81-95.

Pietrzykowski, Z. (2011) 'Maritime intelligent transport systems', Transport Systems Telematics, Vol. 104, pp. 455-462.

Poon, T.C., Choy, K.L., Lau, H.C.W. (2009) 'A RFID case-based logistics resource management system for managing order-picking operations in warehouses', Expert Systems with Applications, Vol. 36 No.4, pp. 8277-8301.

Schumacher, J., Rieder, M., Gschweidl, M., Masser, P. (2011) 'Intelligent cargo-Using Internet of things concepts to provide high interoperability for logistics systems', in D. Uckelmann et al. (eds.), Architecting the internet of things, Springer, pp. 317-347.

Stefansson, G., and Lumsden, K. (2009) 'Performance issues of smart transportation management systems', International Journal of Productivity and Performance Management, Vol. 58 No. 1, pp. 55-70.

Sundarakani, B., Tan, A.W.K., van Over, D. (2012) 'Enhancing the supply chain management performance using information technology: Some evidence from UAE companies', International Journal of Logistics Systems and Management, Vol. 11 No. 3, pp. 306324.

Taniguchi, E., and Shimamoto, H. (2004) 'Intelligent transportation system based dynamic vehicle routing and scheduling with variable travel times', Transportation Research Part C, Vol. 12 No. 3-4, pp. 235-250.

Teodorovic, D., and Lucic, P. (2006) 'Intelligent parking systems', European Journal of Operational Research, Vol. 175 No. 3, pp. 1666-1681.

Thome, T., Vacavant, A., Robinault, L., Miguet, S. (2011) 'A cognitive and video-based approach for multinational license plate recognition', Machine Vision and Applications, Vol. 22 No. 2, pp. 389-407.

Tsugawa, S., Aoki, M., Hosaka, A., Seki, K. (1997) 'A survey of present IVHS activities in Japan’, Control Eng. Practics, Vol. 5 No. 11, pp. 1591-1597. 
Vanderschuren, M. (2008) 'Safety improvements through intelligent transportation systems: A South African case study based on microscope simulation modeling', Accident Analysis and Prevention, Vol. 40 No. 2, pp. 807-817.

Vilko, J., Rumpu, A., Koivuniemi, J. (2012) 'An information-exchange perspective on supply-chain risk management: Systemic organisational motives and cognitive barriers', International Journal of Logistics Systems and Management, Vol. 12 No. 4, pp. 460482.

Wootton, J.R., Garcia-Ortiz, A., Amin, S.M. (1995) 'Intelligent transportation systems, a global perspective', Mathematical Computer Modelling, Vol. 22 No. 4-7, pp. 259-268.

Yin, R.K. (2003) Case study research-Design and methods, Third Edition, SAGE Publications, Thousand Oaks, US.

Zeimpekis, V., Minis, I., Pappa, V. (2010) 'Real-time logistics management of dried figs using RFID technology: Case study in a Greek cooperative company', International Journal of Logistics Systems and Management, Vol. 7 No. 3, pp. 265-285.

\section{Figures}

\section{Figure 1}

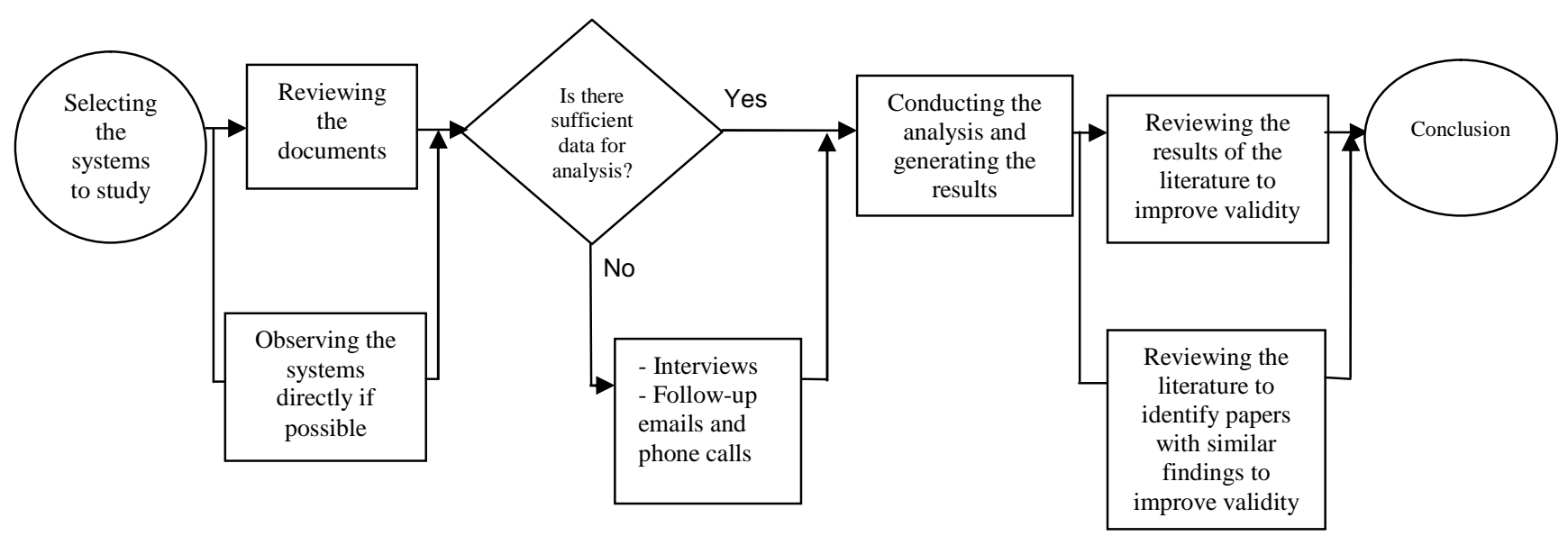

Figure 1. The process of conducting the empirical studies

Figure 2

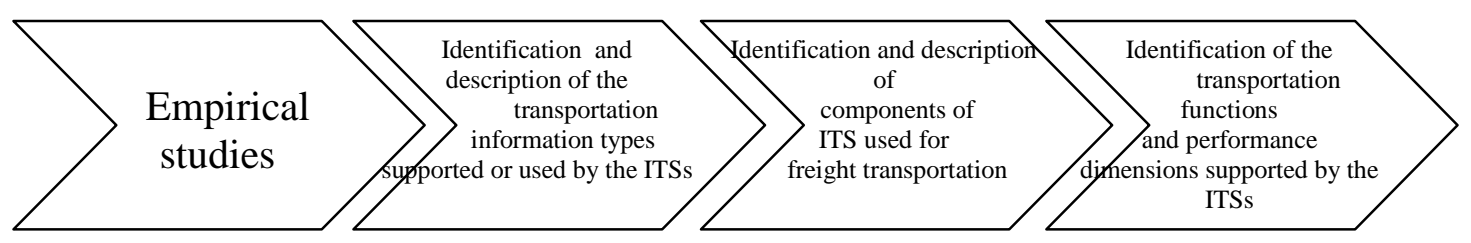

Figure 2. Different steps of analysis conducted in this paper 
Figure 3

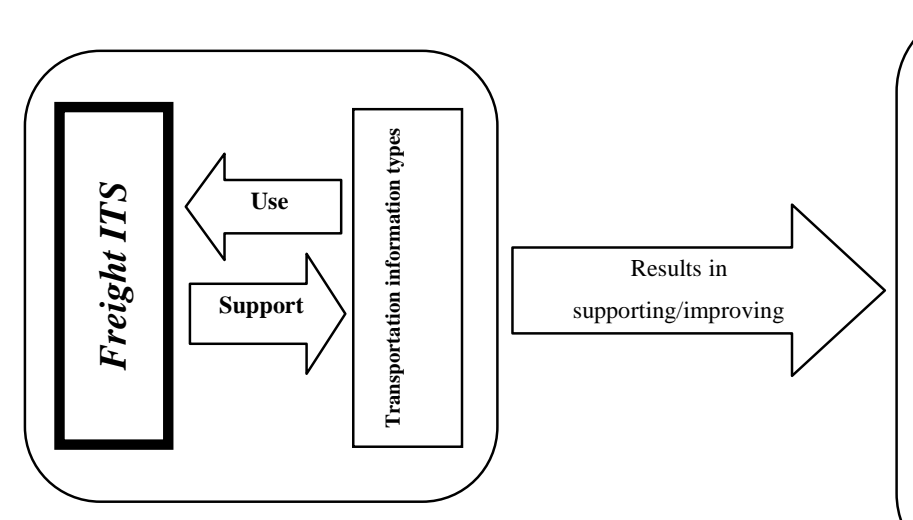

Transportation operations

Functions
- Transportation resource

management

- Port and terminal operations

management

- Freight and vehicle tracking

and tracing

Performance dimensions

- Efficiency and effectiveness

- Safety and security

- Environmental performance

Figure 3. Overview of freight ITS

\section{Tables}

Table 1. Transportation information types supported or used by freight ITS and transportation functions and improved transportation performance dimensions supported by freight ITS.

\begin{tabular}{|c|c|c|c|c|c|c|c|c|c|c|c|c|c|}
\hline \multirow[b]{2}{*}{ Freight ITS } & \multicolumn{7}{|c|}{ Transportation information types } & \multicolumn{3}{|c|}{$\begin{array}{l}\text { Supported transportation } \\
\text { functions }\end{array}$} & \multicolumn{3}{|c|}{$\begin{array}{l}\text { Supported transportation } \\
\text { performance dimensions }\end{array}$} \\
\hline & 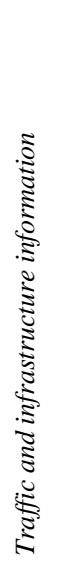 & 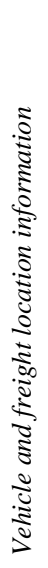 & 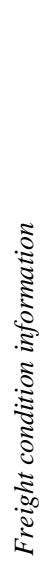 & 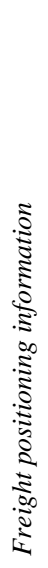 & 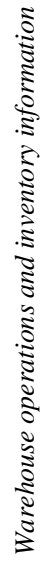 & 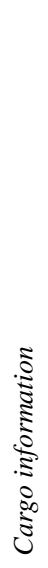 & 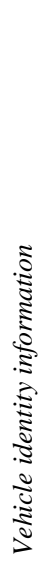 & 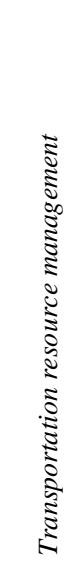 & 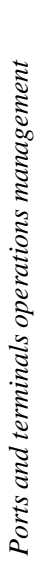 & 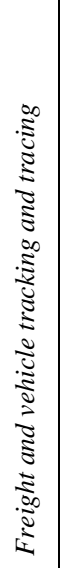 & 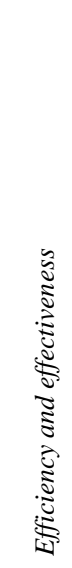 & 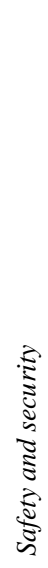 & 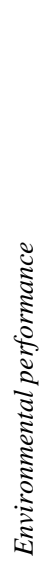 \\
\hline $\begin{array}{l}\text { Traffic control and } \\
\text { monitoring systems }\end{array}$ & $\mathrm{x}$ & & & & & & $\mathrm{x}$ & $\mathrm{x}$ & $\mathrm{x}$ & & $\mathrm{x}$ & $\mathrm{x}$ & $\mathrm{x}$ \\
\hline Weight-in-motion systems & $\mathrm{x}$ & & & & & $\mathrm{x}$ & $\mathrm{x}$ & & & & $\mathrm{x}$ & $\mathrm{x}$ & $\mathrm{x}$ \\
\hline Delivery space booking systems & & $\mathrm{X}$ & & & & & $\mathrm{x}$ & $\mathrm{x}$ & $\mathrm{x}$ & & $\mathrm{x}$ & & $\mathrm{x}$ \\
\hline $\begin{array}{l}\text { Vehicle location and condition } \\
\text { monitoring systems }\end{array}$ & $\mathrm{x}$ & $\mathrm{x}$ & $\mathrm{x}$ & & & $\mathrm{x}$ & $\mathrm{x}$ & $\mathrm{x}$ & $\mathrm{x}$ & $\mathrm{x}$ & $\mathrm{x}$ & $\mathrm{X}$ & \\
\hline Route planning systems & $\mathrm{x}$ & $\mathrm{x}$ & & & & & & $\mathrm{x}$ & & & $\mathrm{x}$ & & $\mathrm{x}$ \\
\hline $\begin{array}{l}\text { Driving behaviour monitoring } \\
\text { and control systems }\end{array}$ & $\mathrm{x}$ & & & & & & $\mathrm{x}$ & $\mathrm{x}$ & & & & $\mathrm{x}$ & $\mathrm{x}$ \\
\hline Crash preventing systems & $\mathrm{x}$ & & & & & & & & & & & $\mathrm{x}$ & \\
\hline
\end{tabular}




\begin{tabular}{|c|c|c|c|c|c|c|c|c|c|c|c|c|c|}
\hline $\begin{array}{l}\text { Freight location monitoring } \\
\text { systems }\end{array}$ & & $\mathrm{x}$ & & $\mathrm{x}$ & $\mathrm{x}$ & $\mathrm{x}$ & & & $\mathrm{x}$ & $\mathrm{x}$ & $\mathrm{x}$ & $\mathrm{x}$ & $\mathrm{x}$ \\
\hline $\begin{array}{l}\text { Freight status monitoring } \\
\text { systems }\end{array}$ & & & $\mathrm{x}$ & $\mathrm{x}$ & $\mathrm{x}$ & $\mathrm{x}$ & & & $\mathrm{x}$ & $\mathrm{x}$ & $\mathrm{x}$ & $\mathrm{x}$ & $\mathrm{x}$ \\
\hline Total & 6 & 4 & 2 & 2 & 2 & 4 & 5 & 5 & 5 & 3 & 7 & 7 & 7 \\
\hline
\end{tabular}

